\title{
Causes and management of urogenital fistulas
}

\section{A retrospective cohort study from a tertiary referral center in Saudi Arabia}

Somaia A. Osman, SBOG, MRCOG, Ahmed H. Al-Badr, FRCSC, FACOG, Ola T. Malabarey, MBBS, FRCSC, Ashraf M. Dawood, BMChB, FRCSC, Badr N. AlMosaieed, MD, MPH, Diaa E.E. Rizk, FRCOG, FRCS.

\begin{abstract}
الأهداف : مراجعة المسببات وعلاج الناسور البولي التناسلي في مركز احالة للرعاية الثالثة.

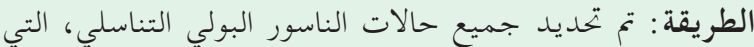

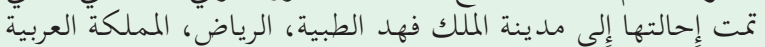

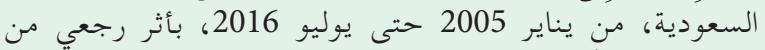

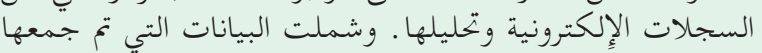

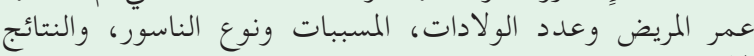

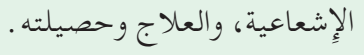

النتائج : من بين 32 حالة من الناسور البولي التناسلي سجلت ، كان كان

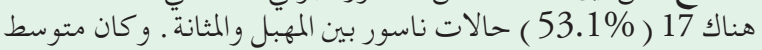

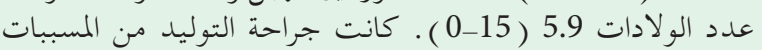

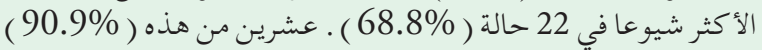

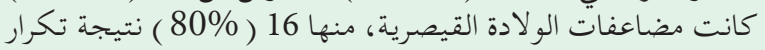

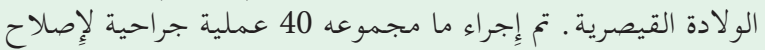

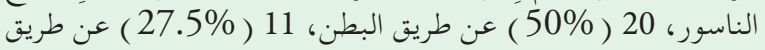

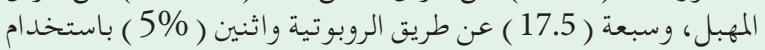

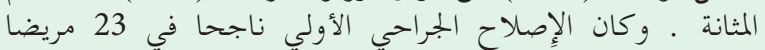

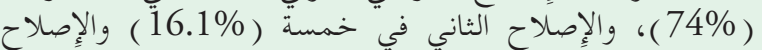

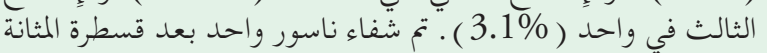

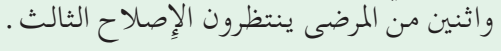

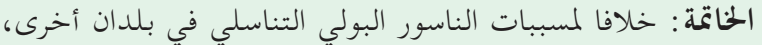

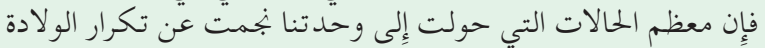

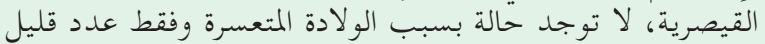

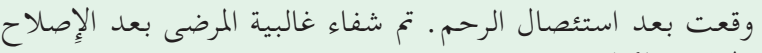
الجراحي الأولية.
\end{abstract}

Objectives: To review the etiology and management of urogenital fistulas at a tertiary care referral center.

Methods: We retrospectively identified all patients with urogenital fistula referred to the King Fahad Medical City, Riyadh, Saudi Arabia, between January 2005 and July 2016 from electronic records. We collected data on age, parity, etiology and type of fistula, radiologic findings, management, and outcome.

Results: Of the 32 patients with urogenital fistula identified, $17(53.1 \%)$ had vesicovaginal fistula. The mean parity was $5.9(0-15)$. Obstetric surgery was the most common etiology, accounting for 22 fistulas (68.8\%). Twenty of these $(90.9 \%)$ were complications of cesarean delivery, of which 16 $(80 \%)$ were repeat cesarean delivery. Forty surgical repair procedures were performed: $20(50 \%)$ via an abdominal approach, $11(27.5 \%)$ via a vaginal approach, $7(17.5)$ via a robotic approach, and 2 $(5 \%)$ using cystoscopic fulguration. The primary surgical repair was successful in 23 patients $(74 \%)$, the second repair in $5(16.1 \%)$, and the third repair in one $(3.1 \%)$. One fistula was cured after bladder catheterization, and 2 patients are awaiting their third repair.

Conclusion: Unlike the etiology of urogenital fistulas in other countries, most fistulas referred to our unit followed repeat cesarean delivery: none were caused by obstructed labor, and only a few occurred after hysterectomy. Most patients were cured after the primary surgical repair.

Saudi Med J 2018; Vol. 39 (4): 373-378 doi: 10.15537/smj.2018.4.21515

From the Department of Urogynecology and Pelvic Reconstructive Surgery (Osman, Al-Badr, Dawood), Women's Specialized Hospital, the Urology Department (AlMosaieed), King Fahad Medical City, Riyadh, Kingdom of Saudi Arabia; from the Department of Obstetrics and Gynecology (Rizk), College of Medicine and Medical Sciences, Arabian Gulf University, Manama, Bahrain; and from the Department of Obstetrics \& Gynecology, Urogynecology \& Pelvic Reconstructive Surgery (Malabarey), McMaster University, Ontario, Canada.

Received 7th November 2017. Accepted 7th March 2018.

Address correspondence and reprint request to: Dr. Ahmed Al-Badr, Urogynecology and Pelvic Reconstructive Surgery Women's Specialized Hospital, King Fahad Medical City, Riyadh, Kingdom of Saudi Arabia. E-mail:aalbadr@kfmc.med.sa ORCID ID: 0000-0002-9088-6014 
U rogenital fistula is a serious surgical complication that causes serious psychologic and social distress and has a negative impact on women's lives. ${ }^{1,2}$ In developing countries, this complication usually is of an obstetric origin such as obstructed or prolonged labor. ${ }^{2}$ In Africa, fistulas with obstetric causes represent $70-96 \%$ of the total number of fistulas, and the incidence of fistula is as high as 3 to 4 cases per 1000 vaginal deliveries. ${ }^{3,4}$ In contrast, in developed countries, $83.2 \%$ of fistula are mainly related to surgery. ${ }^{4} \mathrm{~A}$ previous study performed in Saudi Arabia found that $75 \%$ of urogenital fistulas had an iatrogenic obstetric origin unrelated to obstructed labor, highlighting the contrast between the etiologies of these fistulas in developing and developed countries. ${ }^{5}$ In this study, we reviewed the etiology and management of urogenital fistulas at a tertiary care referral center in Saudi Arabia. We predicted that most urogenital fistulas treated at our institution will be related to iatrogenic obstetric fistula other than would be related to gynecological or prolonged labor such as in developed and developing countries. We anticipate that the results of this study will be used to improve the clinical audit of obstetrics and gynecologic practice in Saudi Arabia and have vital implications for the structure of training in this specialty in the Kingdom.

Methods. We conducted a retrospective cohort study of all patients with urogenital fistulas referred to the Urogynecology and Urology Departments of the King Fahad Medical City, a tertiary referral center in Riyadh, Saudi Arabia, between January 2005 and July 2016. Female patients with urogenital fistulas of all ages were included, whereas patients with conditions other than urogenital fistula, such as rectovaginal fistula, were excluded. The medical coding system was used to identify the medical records of all patients with urogenital fistulas and the data were analyzed.

The data collected from electronic patient charts included age, obstetric history, and referral etiology. All patients underwent a clinical evaluation that included a methylene blue test, urine culture and a sensitivity analysis, cystourethrography, and examination under anesthesia with cystoscopy. Imaging of the upper urinary tract using intravenous pyelography (IVP), computed tomography (CT), and magnetic resonance

Disclosure. Authors have no conflict of interests, and the work was not supported or funded by any drug company. This study was supported by grant the Research Center, King Fahad Medical City, Riyadh, Saudi Arabia. imaging (MRI) was performed in all patients to rule out ureteric injury and ensure the integrity and function of the upper urinary tract. The management options were transurethral bladder catheterization, cystoscopic fulguration, or vaginal, abdominal, or robotic repair, and were chosen according to the type, location, and complexity of the fistula as well as the surgeon's experience. In patients needing surgical intervention, the fistulous tract was identified and excised, and the bladder was repaired in 2 layers with absorbable sutures with interposition of a graft if necessary. Transurethral Foley catheter drainage was continued for 2 to 3 weeks postoperatively. A suprapubic catheter was used when a cystotomy was performed. Perioperative antibiotic prophylaxis was administered to all patients and continued postoperatively if there was any preoperative evidence of urinary tract infection.

Six surgeons performed the fistula repair procedures: 2 urologists and 4 urogynecologists. The outcome was deemed successful with symptomatic cure: a complete absence of urine leakage and normal findings on cystourethrography, IVP, CT, and MRI.

English literature reviewed using PubMed, Cochrane Library, ClinicalKey, and Google Scholar using the following key words: fistula; obstetric; cesarean section; iatrogenic; and urogenital.

Simple statistics (namely percentages) were used to present the results because of the small number of patients involved in the study.

The study was approved by the hospital ethics committee (Approval Reference: IRB16-210).

Results. Thirty-two patients with urogenital fistula were identified over the 12-year study period. The patients were referred to our unit either immediately (3 days) or some time (3-13 years) after the onset of symptoms. The most common symptom was continuous urinary leakage from the vagina that appeared between 3 days to 6 weeks after the incident. One woman with vesicouterine fistula (VUF) presented with cyclic hematuria and recurrent urinary tract infections without urinary incontinence.

The etiologies of the fistulas are presented in Table 1, and the type of fistula, demographic data, and management of patients with fistula are presented in Table 2. Twenty-two fistulas (68.8\%) were due to iatrogenic obstetric causes: 20 of them (90.9\%) were complications of cesarean delivery and due to repeat cesarean section in $80 \%$ (Table 1 ). Two of the cesarean deliveries were followed by uncontrolled hemorrhaging necessitating cesarean hysterectomy. One of the cesarean deliveries was the primary delivery, 
performed for failure to progress in labor, complicated by massive postpartum hemorrhaging, and treated by a subtotal hysterectomy. In the other patient, cesarean hysterectomy was performed as electively for placenta previa and accreta after 2 previous cesareans. Two fistulas followed cervical cerclage ( $\mathrm{McD}$ Donald's technique): one was performed as an emergency at 22 weeks' gestation for twin pregnancy with bulging membranes, and the other was the fifth cerclage operation performed for an incompetent cervix at 14 weeks' gestation. Another obstetric fistula occurred in a patient with spontaneous abortion at 16 weeks' gestation, who had undergone 2 previous cesareans and who developed severe bleeding necessitating a subtotal hysterectomy. The procedure was complicated by a bladder injury that was identified and repaired intra-operatively.

All 10 non-obstetric fistulas were vesicovaginal fistulas (VVFs). Eight followed hysterectomies, 5 of which had been performed for a malignant indication (one ovarian, one cervical, and 3 endometrial cancers). Five of these procedures were abdominal hysterectomy, 2 were laparoscope-assisted vaginal hysterectomy, and one was robot-assisted vaginal hysterectomy. Regarding the remaining 2 non-hysterectomy related fistulas, one was a traumatic fistula following a motor vehicle accident with a pelvic fracture at the sacroiliac joint, and the second was a malignant fistula associated with advanced cervical cancer invading the bladder.

All VUFs were complications of repeat cesarean delivery. Two vesicocervical fistulas (VCFs) were

Table 1 - Etiology of urogenital fistulas.

\begin{tabular}{lrr}
\hline Etiology of fistula & $\mathbf{n}$ & \multicolumn{1}{c}{$(\%)$} \\
\hline Iatrogenic obstetric & $22 / 32$ & $(68.8)$ \\
Cesarean delivery & $20 / 22$ & $(90.9)$ \\
Cervical cerclage & $2 / 22$ & $(9.0)$ \\
Gynecologic & $9 / 32$ & $(28.1)$ \\
Motor vehicle accident & $1 / 32$ & $(3.1)$ \\
\hline
\end{tabular}

complications of repeat cesarean delivery for placenta percreta with bladder invasion. In one of these 2 patients, cesarean hysterectomy was complicated by a bladder injury that was repaired intra-operatively. The third VCF occurred after vaginal birth following a cesarean section, and the fourth after a primary cesarean delivery in the second stage of labor complicated by bladder injury (Table 2).

A total of 40 procedures were performed to repair the fistulas (Table 2). The surgical approach was abdominal in $20(50 \%)$ patients, vaginal in $11(27.5 \%)$, robotic in $7(17.5 \%)$, and cystoscopic in $2(5 \%)$. The size of the fistulas ranged from $2 \mathrm{~mm}$ to $5 \mathrm{~cm}$. One fistula responded to conservative treatment with transurethral bladder drainage. Both uretovaginal fistulas (UVFs) were repaired through the abdominal approach, with ureteric re-implantation. The primary repair was successful in $23(74 \%)$ patients, and the second repair in $5(16.1 \%)$. One patient $(3.2 \%)$ was cured after the third fistula repair (the first and second repairs were conducted via an abdominal approach, whereas the third successful repair was performed vaginally), and $2(6.5 \%)$ are currently awaiting their third repair procedures (Patients 12 and 14; Table 2). The success rate of the primary repair by approach was $80 \%$ for abdominal, $71.4 \%$ for robotic and vaginal, and $50 \%$ for cystoscopic fulguration. In 4 patients, concomitant hysterectomy was performed at the time of abdominal repair because of extensive pelvic adhesions and severe bleeding. In all patients, cystography, CT or MRI was performed to confirm the integrity of the bladder 2 to 3 weeks after surgical repair. When ureteric re-implantation was performed, postoperative IVP was conducted to ensure the absence of ureteric obstruction or stricture.

The mean post-treatment follow-up duration was 13 months (range: 2 months to 3 years). Thirty (93.7\%) fistulas were considered cured based on symptoms and the findings of physical and radiologic investigations.

Table 2 - Type of fistula, demographic data, and management of patients with urogenital fistulas.

\begin{tabular}{|c|c|c|c|c|c|c|c|c|}
\hline \multirow[t]{2}{*}{ Type of fistula } & \multirow[t]{2}{*}{ n $\quad(\%)$} & \multirow[t]{2}{*}{$\begin{array}{l}\text { Age (years) } \\
\text { (range) mean }\end{array}$} & \multirow[t]{2}{*}{$\begin{array}{c}\text { Parity } \\
\text { (range) mean }\end{array}$} & \multicolumn{4}{|c|}{$\begin{array}{c}\text { Procedure } \\
(\mathrm{N}=40) \text { number }\end{array}$} & \multirow{2}{*}{$\begin{array}{l}\text { Need for repea } \\
\text { procedure } \\
\text { n }(\%)\end{array}$} \\
\hline & & & & Abdominal & Vaginal & Robotic & Fulguration & \\
\hline Vesicovaginal fistula & $17(53.0)$ & $(17-62) 43.0$ & $(0-15) 6$ & 9 & 10 & 3 & 2 & $6(35.0)$ \\
\hline Vesicouterine fistula & $6(18.8)$ & $(32-47) 39.0$ & $(3-11) 7$ & 3 & - & 2 & - & 0 \\
\hline Vesicocervical fistula & $4(12.5)$ & (29- -41$) 34.0$ & $(2-6) 4$ & 2 & 1 & 2 & - & $1(25.0)$ \\
\hline Ureterovaginal fistula & $2(6.4)$ & $(43-44) 43.5$ & $(5-8) 7$ & 2 & - & - & - & 0 \\
\hline Multiple & $3 \quad(9.3)$ & $(35-38) 37.0$ & $(3-8) 5$ & 4 & - & - & - & $1(33.3)$ \\
\hline
\end{tabular}


Discussion. This study is the second and largest report from a tertiary center in Saudi Arabia to consider the causes and management of urogenital fistulas. Among the 32 patients referred to our unit, the fistulas of almost two-thirds resulted from iatrogenic obstetric causes, mainly as complications of repeat cesarean delivery, and none were due to obstructed labor. This finding has important implications for the clinical guidelines on cesarean delivery, residency training curricula, and surgical skills necessary to perform repeat cesarean sections imparted obstetric training.

The etiology and incidence of urogenital fistulas vary by geographic region. Neglected obstructed labor is the most common cause in developing countries (up to $97 \%$ of cases), and none are related to iatrogenic obstetric causes. ${ }^{3,4}$ The incidence is estimated to be as high as 3 to 4 patients per 1000 vaginal deliveries, and the condition mainly arises in primiparous women who experience a delay in seeking care and reaching health facilities. ${ }^{3,4,6,7}$ More recently, a growing incidence of iatrogenic obstetric fistulas has been reported in developing countries. ${ }^{8}$ However, it is unclear whether these fistulas are of iatrogenic obstetric origin or caused by ischemia resulting from obstructed labor. The intervention in most of these patients was delayed, and the diagnosis depended on the surgeon's subjective perception of the cause of the fistula. ${ }^{9}$ In developed countries, the most common causes of urogenital fistula are gynecologic surgery and, to a lesser extent, iatrogenic obstetric causes and radiation. The incidence of fistula in these countries ranges from $0.1 \%$ (after simple hysterectomy) to $10 \%$ (after radical hysterectomy). . $^{40}$

Although the World Health Organization designates Saudi Arabia as a developing country, ${ }^{11}$ iatrogenic obstetric causes comprised the majority $(68.8 \%)$ of the urogenital fistulas observed in our study, which were mainly related to repeat cesarean delivery rather than obstructed labor. Vesicovaginal fistulas, however, was the most common type of urogenital fistula found in our patients $(53.1 \%)$, similar to previous reports. All VUF, VCF, UVF, and multiple fistulas in our series were related to cesarean delivery. This relationship is a direct result of the growing rate of cesarean delivery worldwide, and iatrogenic obstetric urogenital fistulas are increasingly encountered in current practice. ${ }^{12,13}$ As seen in our study, Saudi Arabia is a parous society, with a mean parity of 5.9, and most patients refuse sterilization after multiple cesareans. Furthermore, $68 \%$ of patients in Saudi Arabia undergoing elective cesarean section are grand multiparas, and the main indication for elective cesarean delivery is repeated cesarean delivery. ${ }^{14}$ This factor increases the incidence of repeat cesarean deliveries and, hence, the risk of intra-operative trauma to the urogenital tract. In fact, significant increase in cesarean section rate in Saudi Arabia from 12\% to 20\% over short period 2002 to 2009 was observed recently. ${ }^{15}$

In other parts of the world with comparable cesarean section rates such as North America, where the rate is $32.3 \%,{ }^{16}$ most VVF fistulas (82.3\%) have gynecologic causes (hysterectomy). ${ }^{17}$ In countries with even higher cesarean section rates, such as Brazil (55\%), ${ }^{16}$ most genital fistulas are reportedly due to hysterectomy $(15 / 16) ;{ }^{18}$ nevertheless, the majority of these are primary cesarean deliveries. The higher rate of cesareanrelated fistula in this series is likely because most of the cesarean-related fistulas (80\%) were secondary to repeat cesarean deliveries.

Most of the cesarean deliveries reported in our study were complicated by bladder injury $(12 / 20)$. The reported incidence of bladder injury during cesarean section is $0.28 \% .{ }^{19}$ However, the rate of bladder injury rises proportionally with the number of cesarean operations (first: $0.13 \%$; second: $0.09 \%$; third: 0.28\%; fourth: $1.17 \%$; fifth: $1.94 \%$; and sixth: $4.49 \%$ ) because of technical difficulties caused by adhesions. ${ }^{19}$ The injury usually occurs during peritoneal entry and involves the dome of the bladder in most patients. ${ }^{20}$ Other risk factors for bladder injury include emergency or intrapartum cesarean delivery, intra-operative hemorrhaging, failure to empty the bladder before the operation, and anterior placenta previa. ${ }^{19}$ These risk factors were all observed in our patients, and may explain the elevated incidence of bladder injury and urogenital fistulas after multiple cesarean sections. In addition, most of these complications followed cesarean sections performed in rural areas, and so may be related to inadequate resources, exposure to patients who have undergone multiple cesarean sections, and training.

Two VVFs occurred after cervical cerclage, as previously described in the literature. ${ }^{21}$ The risk of this procedure is usually underestimated, and deep or high placement of the cervical suture should, therefore, be avoided. Furthermore, vaginal leakage after cervical cerclage should not be assumed to be the rupture of membranes and must be thoroughly investigated to rule out urogenital fistula. Eight patients developed fistula after hysterectomies, 5 of which had been performed for malignant conditions. The incidence of urinary tract injury during simple hysterectomy is $4.3 \%$, with the bladder accounting for $2 \%$, and this risk is greater in patients with previous cesarean deliveries. ${ }^{22}$ The rate increases for total abdominal hysterectomy and laparoscope-assisted vaginal hysterectomy. ${ }^{24}$ Both findings were seen in our study. Patients were referred 
from different parts of Saudi Arabia, and therefore delays in the referral and acceptance process led to a wide variation in the duration of diagnosis and treatment, ranging from 3-13 years. The patients referred from the same center were all seen within a few days.

Surgery is considered the definitive treatment for urogenital fistulas, but there is no consensus on the optimal timing, surgical approach, or technique of repair. ${ }^{24,25}$ We prefer to perform surgical repair within 6-8 weeks of the incident, after a conservative trial of continuous bladder drainage using a Foley catheter to allow complete healing of the tissues with the aims of improving the success rate of surgical repair and allowing for spontaneous closure of the fistula. This management was successful in one patient with a small VUF, who presented early (day 3 after her third cesarean section) with a wound that was still fresh. However, this measure was not taken in patients who presented late, because at this point spontaneous resolution is unlikely. Two other patients were managed by cystoscopic fulguration: the first, successful fulguration was performed in a patient with a small VVF, whereas the second, unsuccessful fulguration was performed in a patient receiving radiotherapy, who subsequently required an abdominal repair.

Our surgical approach and technique were based on the type of fistula, number of previous repair attempts, ease of access, and experience of the surgeon. Although most of the fistulas reported in our study were VVF, use of the vaginal approach was uncommon, because all VVFs were related to either hysterectomy or cesarean delivery rather than prolonged or obstructed labor. Therefore, all were located in the vaginal vault. The surgical approach to repair was selected according to the preference of the surgeon, and the abdominal repair was preferred for its ease of access. The outcome was similar to those of other reports, with a cure rate after the first surgical repair of $74 \% .^{24,25}$

Obstetricians should be aware of pelvic anatomy, identify patients at risk of urinary tract injury through the use of tests such as cystoscopy, dye tests, and retrograde pyelography, and consult a urologist when necessary. ${ }^{26}$ Structured residency training with greater exposure to difficult cesareans, particularly in women who have undergone multiple cesareans or have placenta previa and accreta, is needed. Also, patients with these conditions must be referred to centers where expert surgeons are available and a multidisciplinary approach is possible to reduce the frequency of injuries to the lower urinary tract. Repeated cesarean delivery is a significant risk factor for bladder injury, and women should be counseled regarding this fact before the operation.

Study limitations. The limitations of our study include its retrospective design and single-center nature; further studies involving hospitals throughout Saudi Arabia are needed to identify the main causes of urogenital fistulas. However, this study represents the largest urogenital fistula series to have been reported in the region, and provides new valuable insights into the etiologies of obstetric fistulas.

In conclusion, our study showed that the majority of urogenital fistulas treated at our center are associated with iatrogenic obstetric causes and none are due to obstructed labor, unlike in developing countries. Most fistulas were cured after the first surgical repair.

\section{References}

1. Saadalla AM, Mirghani HO. Psychosocial impact among Sudanese women with vesico-vaginal fistula. Frontiers in Cognitive Psychology 2017; 2: 10-12.

2. Umeora OUJ, Emma-Echiegu NB. Vesico-vaginal fistula in developing countries - time to turn off the tap. J Preg Child Health 2015; 2: e120.

3. Pradhan HK, Dangal G, Karki A, Shrestha R, Bhattachan K. Experience of managing urogenital fistula. NJOG 2014; 9: 17-20.

4. Hillary CJ, Osman NI, Hilton P, Chapple CR. The aetiology, treatment, and outcome of urogenital fistulae managed in well- and low-resourced countries: A systematic review. Eur Urol 2016; 70: 478-492.

5. Perveen K, Al-Shaikh G, Al-Moazin M, Ross S, Al-Badr A. Urogenital fistula in a Saudi Arabian referral center. Arch Gynecol Obstet 2013; 287: 261-265.

6. Sori DA, Azale AW, Gemeda DH. Characteristics and repair outcome of patients with vesicovaginal fistula managed in Jimma University teaching Hospital, Ethiopia. BMC Urol 2016; 16: 41.

7. Roka ZG, Akech M, Wanzala P, Omolo J, Gitta S, Waiswa P. Factors associated with obstetric fistulae occurrence among patients attending selected hospitals in Kenya, 2010: a case control study. BMC Pregnancy Childbirth 2013; 13: 56.

8. Hilton P. Trends in the aetiology of urogenital fistula: a case of 'retrogressive evolution'? Int Urogynecol J 2016; 27: 831-837.

9. Onsrud M, Sjøveian S, Mukwege D. Cesarean delivery-related fistulae in the Democratic Republic of Congo. Int J Gynaecol Obstet 2011; 114: 10-14.

10. Garely AD, Mann WJ Jr. Urogenital tract fistula in women. [Updated 2018 January 20. Accessed 22018 March 2]. Available from URL: http://www.uptodate.com/contents/ urogenital-tract-fistulas-in-women.

11. World Health Organization. List of Member States by WHO region and mortality stratum [Accessed 2017 January 30]. Available from URL: www.who.int/whr/2003/en/member_ states_182-184_en.pdf.

12. World Health Organization. WHO statement on caesarean section rates [Updated 2015; Accessed 2017 January 30]. Available from URL: http://apps.who.int/iris/ bitstream/10665/161442/1/WHO_RHR_15.02_eng.pdf. 
13. Raassen TJ, Ngongo CJ, Mahendeka MM. Iatrogenic genitourinary fistula: an 18-year retrospective review of 805 injuries. Int Urogynecol J 2014; 25:1699-1706.

14. Al Rowaily MA, Alsalem FA, Abolfotouh MA. Cesarean section in a high-parity community in Saudi Arabia: clinical indications and obstetric outcomes. BMC Pregnancy Childbirth 2014; 14: 92.

15. Al-Kadri HM, Al-AnaziS A, Tamim HM. Increased cesarean section rate in Central Saudi Arabia: a change in practice or different maternal characteristics. Int J Womens Health 2015; 7: 685-692.

16. Betrán AP, Ye J, Moller AB, Zhang J, Gülmezoglu AM, Torloni $M R$. The increasing trend in caesarean section rates: global, regional and national estimates: 1990-2014. PLoS One 2016; 11: e0148343.

17. Oakley SH, Brown HW, Greer JA, Richardson ML, Adelowo A, Yurteri-Kaplan L, et al. Management of vesicovaginal fistulae: a multicenter analysis from the fellows' pelvic research network. Female Pelvic Med Reconstr Surg 2014; 20: 7-13.

18. Lima Junior MM, Barbosa CS, Lima MM, Granja F. Genital fistula: A case series report from a teaching hospital in Roraima. Brazil. Asian Journal of Pharmaceutical Technology and Innovation 2014; 02: 71-76.

19. Tarney CM. Bladder injury during cesarean delivery. Curr Womens Health Rev 2013; 9: 70-76.
20. Salman L, Aharony S, Shmueli A, Wiznitzer A, Chen R, Gabbay-Benziv R. Urinary bladder injury during cesarean delivery: Maternal outcome from a contemporary large case series. Reproductive Biology 213; June: 26-30

21. Wall LL, Khan F, Adams S. Vesicovaginal fistula formation after cervical cerclage mimicking premature rupture of membranes. Obstet Gynecol 2007; 109: 493-494.

22. Duong TH, Patterson TM. Lower urinary tract injuries during hysterectomy in women with a history of two or more cesarean deliveries: a secondary analysis. Int Urogynecol J 2014; 25: 1037-1040.

23. Mamik MM, Antosh D, White DE, Myers EM, Abernethy M, Rahimi S, et al. Risk factors for lower urinary tract injury at the time of hysterectomy for benign reasons. Int Urogynecol J 2014; 25: 1031-1036.

24. Bohoussou E, Dia JM, Okon G, Djanhan L, Kouamé B, Djanhan Y, et al. Results of the management of urogenital fistulae from community caravans. Open Journal of Obstetrics and Gynecology 2017; 7: 858-865.

25. Ghoniem GM, Warda HA. The management of genitourinary fistula in the third millennium. Arab J Urol 2014; 12: 97-105.

26. Cohen SL, Moulder JK. Preventing urinary tract injury at the time of hysterectomy. Four strategies for success [Updated 2013; Accessed 2018 March 2]. Available from URL: http:// contemporaryobgyn.modernmedicine.com/contemporaryobgyn/news/modernmedicine/modern-medicine-featurearticles/preventing-urinary-tract-inj.

\section{Withdrawal policy}

By submission, the author grants the journal right of first publication. Therefore, the journal discourages unethical withdrawal of manuscripts from the publication process after peer review. The corresponding author should send a formal request signed by all co-authors stating the reason for withdrawing the manuscript. Withdrawal of a manuscript is only considered valid when the editor accepts, or approves the reason to withdraw the manuscript from publication. Subsequently, the author must receive a confirmation from the editorial office. Only at that stage, are the authors free to submit the manuscript elsewhere.

No response from the authors to all journal communication after review and acceptance is also considered unethical withdrawal. Withdrawn manuscripts noted to have already been submitted or published in another journal will be subjected to sanctions in accordance with the journal policy. The journal will take disciplinary measures for unacceptable withdrawal of manuscripts. An embargo of 5 years will be enforced for the author and their co-authors, and their institute will be notified of this action. 